\title{
Utilidad clínica de la medición de la hormona antimülleriana en las mujeres
}

Clinical utility of the measurement

of the Anti-müllerian hormone in women

Carolina Henao-Ochoa MD', Juan D. Lasprilla-Tovar MD', Juan M. Alfaro-Velásquez MD', Germán Campuzano-Maya MD ${ }^{4}$

Resumen: la hormona antimülleriana es una glicoproteína homodimérica perteneciente a la superfamilia del factor de crecimiento transformantes beta (TGF-B). Esta hormona desempeña un papel fundamental en la regresión de los conductos müllerianos en el embrión masculino. En los niños se produce en los testículos, por las células de Sertoli, hasta la pubertad y a partir de alli disminuye lentamente a valores residuales por el resto de la vida. En las mujeres la hormona antimülleriana es secretada por las células de la granulosa de pequeños folículos en el ovario, donde sus niveles reflejan con exactitud la reserva folicular ovárica. Por tal motivo, esta hormona es considerada un marcador extremadamente sensible del envejecimiento ovárico y una herramienta valiosa en el diagnóstico y el reconocimiento de la recurrencia de tumores de células de la granulosa. La evaluación de la hormona antimülleriana también es de importancia clínica en la predicción de la respuesta ovárica, el cese de la función ovárica y la reproducción asistida. Además, puede servir como marcador diagnóstico del síndrome de ovario poliquístico, en los casos en que el examen ultrasonográfico no sea posible de realizar. Finalmente, la medición de los niveles séricos de la hormona antimülleriana, durante la vida reproductiva de la mujer, representa una herramienta ideal para la evaluación de la reserva folicular ovárica. En esta revisión se presenta el rol fisiológico de la hormona antimülleriana en las mujeres, al igual que las principales utilidades clínicas de su medición y las pruebas de laboratorio disponibles para este fin.

Palabras clave: hormona antimülleriana, mujeres, reserva ovárica, síndrome del ovario poliquístico, obesidad, envejecimiento ovárico, marcador tumoral.

Henao-Ochoa C, Lasprilla-Tovar JD, Alfaro-Velásquez JM, Campuzano-Maya G. Utilidad clínica de la medición de la hormona antimülleriana en las mujeres. Medicina \& Laboratorio 2017; 23: 213-236.

\footnotetext{
${ }^{1}$ Médica, especialista en Pediatría, residente de Endocrinología Pediátrica, Universidad de Antioquia. Medellín, Colombia. Correo electrónico: carolinahenaoochoa@gmail.com

${ }^{2}$ Médico, especialista en Pediatría, residente de Endocrinología Pediátrica, Universidad de Antioquia. Medellín, Colombia. ${ }^{3}$ Médico, especialista en Pediatría y Endocrinología Pediátrica. Director Departamento de Endocrinología Pediátrica, Universidad de Antioquia. Medellín, Colombia.

${ }^{4}$ Médico, especialista en Hematología y Patología Clínica. Docente Ad Honorem, Facultad de Medicina, Universidad de Antioquia. Coordinador Grupo de Investigación en Patología Clínica. Médico Director, Laboratorio Clínico Hematológico. Medellín, Colombia. Correo electrónico: gcm@/ch.co

Conflicto de intereses: los autores declaran que no tienen conflictos de intereses Medicina \& Laboratorio 2017; 23: 213-236

Módulo 1 (La Clínica y el Laboratorio), número 122. Editora Médica Colombiana S.A. $2017^{\circ}$ Recibido el 18 de mayo de 2017; aceptado el 06 de junio de 2017
} 
a hormona antimülleriana es un miembro de la familia del factor de crecimiento transformante beta (TGF- $\beta$ ), secretada esencialmente por las células de Sertoli fetales y prepuberales en los hombres, y por las células de la granulosa en las mujeres [1]. Esta hormona desempeña un papel fundamental en la formación y desarrollo de los genitales masculinos, al desencadenar la regresión de los conductos müllerianos fetales, por lo que su ausencia en los hombres produce la persistencia de estas estructuras, lo que conduce a alteraciones que pueden ir desde trastornos funcionales mínimos hasta graves malformaciones anatómicas [1,2].

A pesar de que se le ha dado un papel más protagónico en el hombre, la hormona antimülleriana ejerce gran importancia en la mujer. Es un marcador importante de la reserva y función ovárica, el envejecimiento ovárico y la falla del mismo. Además, ha demostrado ser importante para el diagnóstico y seguimiento de pacientes con síndrome de ovario poliquístico, sometidas a radioterapia, quimioterapia o cirugía ovárica, y con obesidad, entre muchas otras más aplicaciones clínicas importantes [3-5] que serán revisadas en este módulo, junto con las principales técnicas para su medición.

\section{Desarrollo normal del sistema reproductivo}

Antes de abordar las condiciones en las que la hormona antimülleriana tiene valor clínico, es importante conocer cómo es el desarrollo del sistema reproductivo en condiciones fisiológicas normales. Este proceso inicia a las cuatro o cinco semanas de la gestación y se completa después de la pubertad, con la adquisición de las características sexuales secundarias y la fertilidad.
El desarrollo sexual de este sistema es un proceso dinámico, que incluye la interacción de muchos genes, proteínas, moléculas de señalización, factores paracrinos y endocrinos [6].

La determinación sexual corresponde al proceso mediante el cual una gónada bipotencial se desarrolla en un testículo o en un ovario, la cual requiere el desarrollo de una gónada apropiadamente funcional que produzca hormonas y esteroides, que ejerzan un efecto subsecuente en el desarrollo de los genitales [6,7]. Por su parte, la determinación del sexo gonadal, como tal, denota el desarrollo del tejido gonadal como ovario o testículo e implica la formación de la gónada bipotencial, la migración de las células germinales primordiales $y$, finalmente, en el caso de la mujer, la maduración del ovario $[6,8]$.

La gónada primitiva se forma a partir de la condensación de la región medioventral de la cresta urogenital a las cuatro o cinco semanas de gestación, y se separa del primordio suprarrenal a las cinco semanas, aunque continúa siendo bipotencial (indiferenciada) hasta 42 días después de la concepción. Los testículos y los ovarios son morfológicamente indistinguibles hasta cerca de la semana seis posconcepción [6,9].

Las células germinales primordiales corresponden a los precursores embrionarios de los gametos (espermatozoides en los hombres y ovocitos en las mujeres). Específicamente, en el ovario en formación las células germinales femeninas, conocidas como ovogonias, son sometidas a varios ciclos de mitosis y meiosis que son esenciales para dar lugar a los ovocitos, a la posterior diferenciación de las células prefoliculares a las células foliculares y al mantenimiento del desarrollo ovárico. Entretanto, las cé- 
lulas germinales masculinas parece que se encuentran protegidas de las señales que estimulan su diferenciación hacia ovocitos, gracias a su ubicación en el cordón testicular y a la expresión de isoenzimas inhibitorias por parte de las células de Sertoli $[6,10]$.

\section{Desarrollo del ovario y diferenciación sexual femenina}

El desarrollo ovárico es un proceso activo que requiere la expresión de un grupo de genes y factores específicos ( $p$. ej. el gen ovárico RSPO1, que codifica para la Respondina-1), algunos de ellos necesarios para impedir activamente el desarrollo testicular [11]. Tanto el desarrollo del ovario como la diferenciación sexual femenina son procesos menos pronunciados que sus equivalentes masculinos, y no implican cambios significativos en los genitales externos. En las mujeres, las estructuras müllerianas presentes en el estadio indiferenciado persisten para formar las trompas de Falopio, el útero y la porción superior de la vagina, mientras que las estructuras wolffianas se degeneran debido a la ausencia de producción local de testosterona. En los hombres, las estructuras müllerianas desaparecen y las estructuras wolffianas se transforman en los epidídimos, los conductos deferentes y las vesículas seminales (véase figura 1) [6].

Por su parte, las demás estructuras sufren diferentes trasformaciones, donde en las mujeres el seno urogenital se convierte en la uretra y la porción inferior de la vagina, el tubérculo genital en el clítoris, los pliegues urogenitales (uretrales) en los labios menores y las protuberancias urogenitales (labioescrotales) en los labios mayores, y en los hombres la próstata y la uretra prostáti- ca derivan del seno urogenital, el tubérculo genital pasa a ser el glande peniano, los pliegues urogenitales (uretrales) se fusionan para formar el tallo del pene y las protuberancias urogenitales (labioescrotales) forman el escroto (véase figura 2) [6,12].

El ovario en desarrollo, a diferencia del testículo, no expresa receptores de la hormona folículo estimulante (FSH) ni la hormona luteinizante/hormona gonadotrópica coriónica (LH/hCG) hasta después de las 16 semanas de gestación. Alrededor de las 20 semanas, las concentraciones plasmáticas de la FSH alcanzan su nivel máximo y se forman los primeros folículos primarios [6]; para las 25 semanas el ovario presenta sus características morfológicas definitivas. Para el tercer trimestre la foliculogénesis puede continuar, incluso para este momento se pueden haber desarrollado unos pocos folículos de Graaf [8]. Se ha descrito que el ovario fetal inicial también produce esteroides; no obstante, la cantidad de los estrógenos secretados es probablemente insignificante, en comparación con la síntesis placentaria de estrógenos; además, se cree que el ovario permanece quiescente, por lo general, hasta la pubertad [9].

El desarrollo sexual femenino intrauterino se puede afectar por varios trastornos, donde la exposición del feto a los andrógenos conduce a la androgenización de los genitales externos, aun cuando hay útero; no obstante, las estructuras wolffianas no se estabilizan pues la concentración local de testosterona es insuficiente. Esta androgenización de un feto 46 , (femenino) se produce como resultado de trastornos de la esteroidogénesis suprarrenal ( $p$. ej. déficit de la 21-hidroxilasa [CYP21] o de la 11ß-hidroxilasa) o por efectos androgénicos leves luego de la conversión de la 


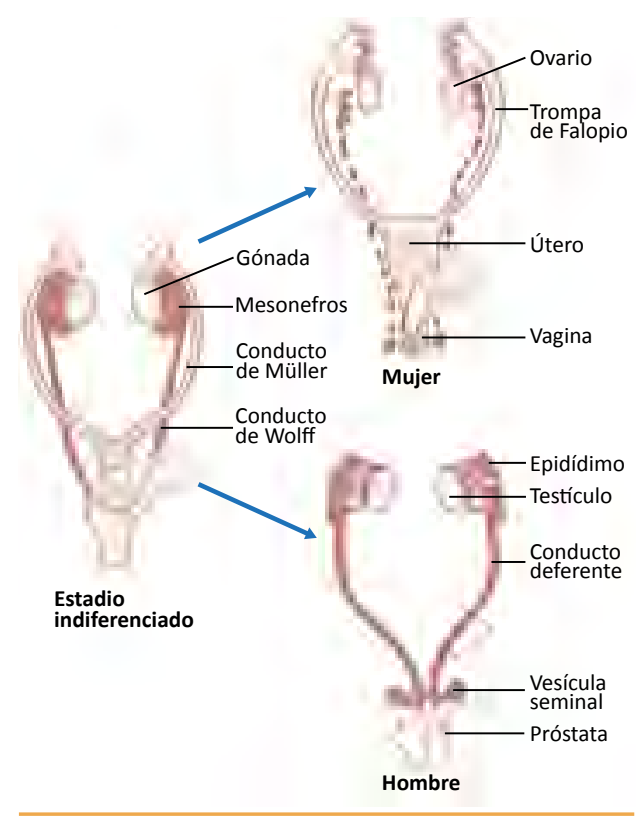

Figura 1. Diferenciación embrionaria de los conductos genitales femeninos y masculinos. Tomado y modificado de Williams Tratado de endocrinología + ExpertConsult (p. 905) por S. Melmed y colaboradores (eds.), 2017, Barcelona, España: Elsevier. Copyright ${ }^{\circledR} 2017$ por Elsevier Inc [6].

dehidroepiandrosterona (DHEA) en exceso, en el déficit de la $3 \beta$-hidroxiesteroide deshidrogenasa (HSD3B2). Otras causas menos frecuentes de androgenización son el déficit de aromatasa, la resistencia a los glucocorticoides, los trastornos de la diferenciación sexual ovotesticulares y los tumores maternos virilizantes (p. ej. luteoma de la gestación), entre otros [6].

\section{Características de la hormona antimülleriana}

La hormona antimülleriana, también conocida como sustancia inhibidora mülleriana, fue reportada por primera vez en 1940, por Alfred Jost, quien la describió como una sustancia proteínica formada en los testículos
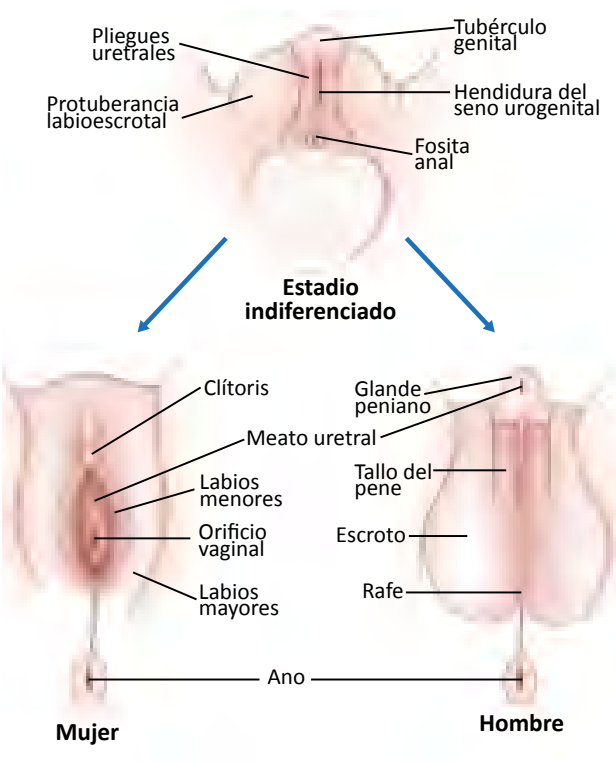

Figura 2. Diferenciación de los genitales externos masculinos y femeninos. Tomado y modificado de Williams Tratado de endocrinología + ExpertConsult (p. 906) por S. Melmed y colaboradores (eds.), 2017, Barcelona, España: Elsevier. Copyright (C) 2017 por Elsevier Inc [6].

de los mamíferos, incluyendo al hombre, responsable de la regresión de los conductos müllerianos [13]. Pasaron casi 40 años para que la proteína y el gen que la codifica fueran aislados y caracterizados; poco después, se describieron sus receptores [14].

La hormona antimülleriana es un péptido que pertenece a la familia del factor de crecimiento transformante beta (TGF- $\beta$ ), producida como un precursor proteínico. Desde el punto de vista químico, es un péptido homodimérico, con un peso molecular de $140 \mathrm{kDa}$, que consta de dos subunidades de glicoproteínas idénticas conectadas por puentes disulfuro (véase figura 3) $[5,13]$. Específicamente, esta hormona está compuesta por dos homodímeros $\mathrm{N}$-terminales de $55 \mathrm{kDa}$ cada uno, denominados la prorregión, y dos C-terminales 


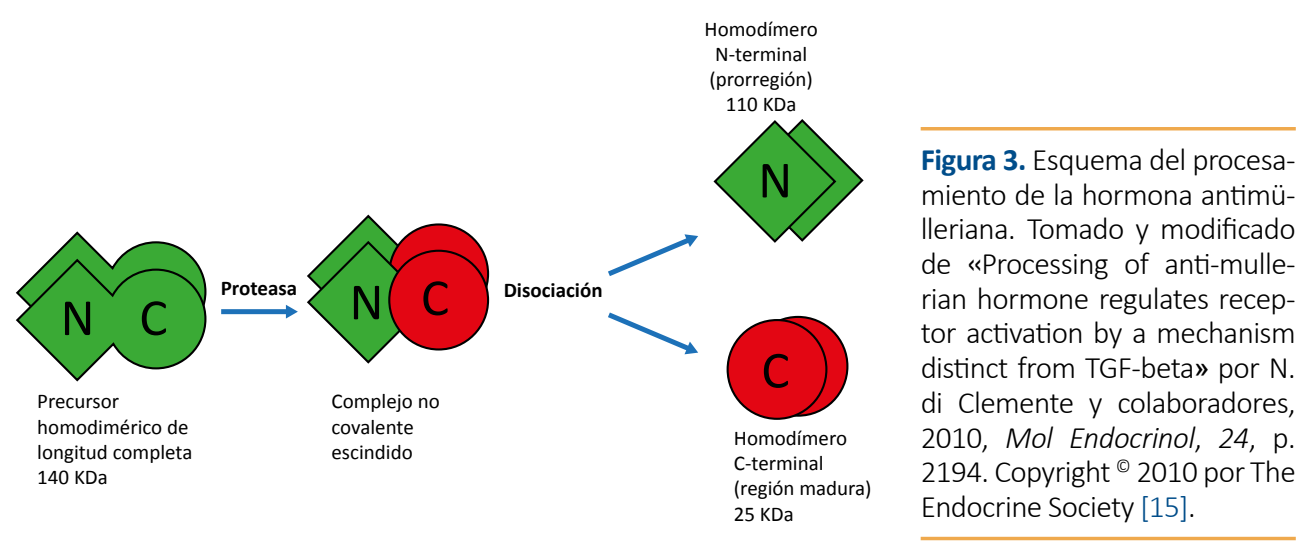

de 12,5 kDa cada uno, correspondiente a la región madura, que pueden ser obtenidos por procesamiento proteolítico de la proteína completa. En circulación, los homodímeros $\mathrm{N}$-terminales y C-terminales se asocian en un complejo no covalente [15].

El gen de la hormona antimülleriana humana se localiza en el brazo corto del cromosoma 19, se compone por 2.750 pares de bases y se encuentra dividido en cinco exones. El extremo 3' del quinto exón, en la región madura, codifica para la parte biológicamente activa de la molécula y es rico en contenido de guanina-citosina [14]; no obstante, la prorregión participa en la estabilidad y el plegado de las proteínas y se considera necesaria para que la hormona tenga su actividad completa [3]. Se ha reportado que el complejo escindido no covalente de la hormona antimülleriana es la forma activa de la proteína que se une a su receptor, el receptor tipo II de la hormona antimülleriana (AMH-RII), y estimula la señalización intracelular [15], que genera una respuesta biológica específica $[1,5,13]$, la cual será descrita más adelante.

El gen que codifica para el receptor tipo II de la hormona antimülleriana (AMH-RII) es codificado en el cromosoma 12 y se compone de 11 exones de más de 8.000 pares de bases de longitud [14]. Este es un receptor proteínico transmembrana heteromérico, compuesto por dos subtipos (tipo I y tipo II), presente en la membrana celular de las células mesenquimales de los conductos müllerianos, las células de la granulosa del ovario y las células de Sertoli y de Leydig de los testículos [16]. Al igual que todos los receptores de factores de crecimiento de la familia del TGF- $\beta$ no utiliza proteínas $\mathrm{G}$ para la transmisión de señales y posee una actividad de serina-treonina quinasa intrínseca $[1,5,13]$.

\section{Producción y función de la hormona antimülleriana en las mujeres}

El papel fisiológico más claramente definido de la hormona antimülleriana es en la diferenciación del sexo masculino, donde es producida por las células de Sertoli fetales para inducir la regresión de los conductos müllerianos, mientras que en ausencia de la hormona, los conductos müllerianos persisten y se transforman en las estructuras femeninas, como ya se describió $[16,17]$. No obstante, el papel de la hormona antimülleriana en el hombre no es revisado en este módulo. En los fetos femeninos la hormona 
antimülleriana aparece en el tejido ovárico a partir de la semana 36 de gestación $[5,16]$ y sus niveles se mantienen durante la infancia y la adolescencia, incluso durante la transición a la pubertad $[16,18,19]$.

La estabilidad en los niveles de la hormona antimülleriana en la infancia, a pesar de la extensa pérdida de los folículos primordiales durante esta etapa, se ha atribuido a una mayor tasa de reclutamiento de los mismos, lo que provee de más folículos productores de la hormona antimülleriana, al igual que al crecimiento folicular inducido por la FSH al momento de iniciar la pubertad, donde los folículos continúan su crecimiento más allá de las etapas en las que se produce la hormona antimülleriana $[16,20]$. En la mujer adulta, los niveles circulantes de la hormona antimülleriana son un reflejo del número de folículos primordiales existentes [16,21], y se conservan hasta la menopausia.

La hormona antimülleriana en las mujeres es producida por las células de la granulosa ovárica de los pequeños folículos en crecimiento (preantrales y antrales pequeños) $[16,22]$, luego del reclutamiento inicial de los folículos primordiales en los que parece no se expresa [23]. En los folículos antrales las concentraciones de la hormona se reducen gradualmente a medida que aumenta su diámetro $[24,25]$, con una gran reducción cuando alcanzan un diámetro de aproximadamente $8 \mathrm{~mm}[25,26]$. Igualmente, se produce una rápida disminución de la expresión de la hormona antimülleriana cuando los folículos alcanzan un grado de diferenciación en el que son seleccionados para dominancia; momento que se caracteriza por la transición de un estado productor de bajos niveles de estrógenos a uno de rápido aumento en la producción de los mismos [3,22] (véase figura 4).

Durante los estadios del crecimiento folicular dependientes de la FSH, la hormona antimülleriana se deja de expresar, excepto en las células del cúmulo de los folículos preovulatorios, donde persiste la expresión [22]. Específicamente, en los folículos antrales grandes la FSH induce la expresión de la aromatasa (Cyp19a1) para producir estradiol, el cual es indispensable para la reducción de los niveles de la hormona antimülleriana a través de la unión al receptor de estradiol-beta (ERß), que interactúa con la región promotora de la hormona para inhibir su expresión [27] (véase figura 4).

Entre las funciones que ejerce la hormona antimülleriana se ha demostrado, en los ratones hembra, que inhibe el reclutamiento inicial y el crecimiento de los folículos primordiales [28]. En ausencia de la hormona antimülleriana los ovarios contienen más folículos en crecimiento [29], con una mayor tasa de reclutamiento cíclico [28], por lo que se considera que desempeña un papel importante en el mantenimiento de la reserva de folículos primordiales [23]. No obstante, los ratones deficientes de la hormona antimülleriana tienen una tasa de ovulación normal, la cual es explicada por el aumento en la degeneración de los ovocitos y en la atresia folicular que neutraliza el aumento del reclutamiento inicial y cíclico para que se produzca un número normal de folículos preovulatorios [29]. Lo anterior, sugiere que la hormona antimülleriana también puede ser un factor de supervivencia para los pequeños folículos en crecimiento [3].

La hormona antimülleriana también reduce in vivo la sensibilidad de los folículos 


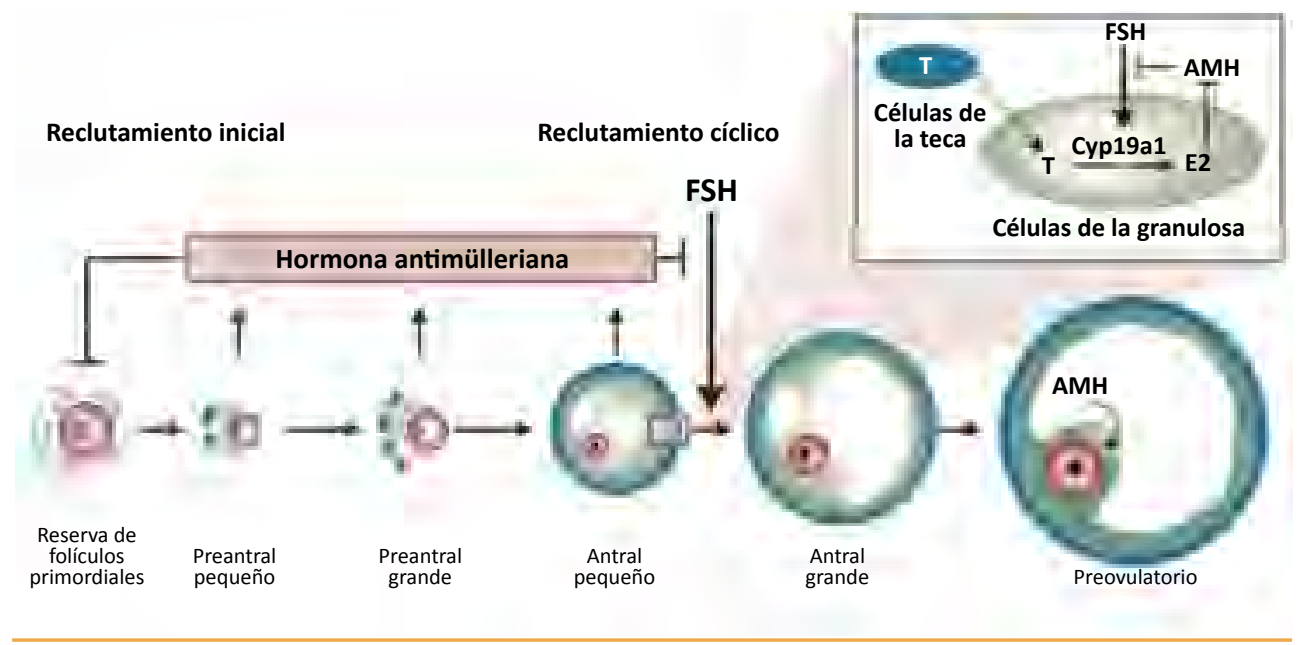

Figura 4. Esquema de la producción y el efecto de la hormona antimülleriana en el ovario. T: testosterona, Cyp19a1: aromatasa, E2: estradiol, AMH: antimülleriana, FSH: hormona folículo estimulante. Tomado y modificado de "Role of Anti-Mullerian Hormone in pathophysiology, diagnosis and treatment of Polycystic Ovary Syndrome: a review" por A. Dumont y colaboradores, 2015, Reprod Biol Endocrinol, 13, p. 2. Copyright ${ }^{\circledR} 2015$ Dumont y colaboradores. Creative Commons Attribution 4.0 International License [22].

ováricos a la FSH y atenúa in vitro el crecimiento folicular preantral estimulado por esta hormona [26]. De esta manera, es evidente que la hormona antimülleriana está implicada en la regulación del inicio del crecimiento folicular y el umbral para la sensibilidad a la FSH $[3,26]$. Por su parte, la hormona antimülleriana participa en la regulación de la esteroidogénesis ovárica en las células de la granulosa, mediante la inhibición de la expresión de la aromatasa (Cyp19a1) inducida por el FSH, lo que conduce a la disminución de las concentraciones de estradiol intrafoliculares [30,31], hasta el momento de la selección folicular, donde aumenta su producción $[3,22]$.

En resumen, la hormona antimülleriana, estimulada por múltiples factores incluyendo la FSH, asegura que cada folículo antral pequeño produzca poco estradiol bajo la influencia de la FSH, mediante la inhibición de la aromatasa antes de la selección, es decir, hasta obtener un diámetro folicular de aproximadamente $8 \mathrm{~mm}$. Entretanto, en los folículos en crecimiento, con diámetros superiores a $8 \mathrm{~mm}$, se produce una abrupta disminución de la hormona antimülleriana, funcionalmente vinculada con el aumento en la producción de estradiol, el cual es capaz de inhibirla completamente a través de ER $\beta$ y superar el estímulo de la $\mathrm{FSH}$, y con el reclutamiento del folículo dominante $[22,25,27]$. Lo anterior, permite establecer un diálogo ovario/hipófisis directo que regula el desarrollo del folículo seleccionado, que será destinado a la ovulación en el momento adecuado, donde la hormona antimülleriana participa como guardián folicular [3].

\section{Niveles séricos de la hormona antimülleriana en mujeres sanas}

Las fluctuaciones en los niveles séricos de la hormona antimülleriana se han encontrado 
en una serie de condiciones fisiológicas, las cuales deben tenerse en cuenta al interpretar sus valores en la práctica clínica. Existe una alta variabilidad interindividual en los niveles de la hormona antimülleriana de acuerdo con la edad [32,33], debido a la diferencia en el número de folículos antrales de las mujeres de distintos grupos etarios [33], los cuales tienden a disminuir, especialmente después de los 40 años [34]. A su vez, pueden presentarse variaciones según la etnia; las mujeres afroamericanas e hispanas tienden a tener niveles más bajos de la hormona antimülleriana que las mujeres caucásicas [35,36].

Algunos estudios han indicado que también existe una relación negativa entre el índice de masa corporal (IMC) y la hormona antimülleriana [37-39]. Sin embargo, esta asociación ha sido descartada por otros [4044]. En cuanto a la relación del tabaquismo y la hormona antimülleriana se han encontrado resultados contradictorios. Algunos estudios informan niveles más bajos de la hormona antimülleriana en mujeres fumadoras $[45,46]$, mientras que otros muestran valores similares a los de aquellas no fumadoras $[42,43,47-49]$.

La mayoría de estudios indican que los niveles de la hormona antimülleriana son relativamente estables a través de las fases del ciclo menstrual [50-52]. No obstante, la dinámica de aparición de la hormona antimülleriana a lo largo del ciclo menstrual ha demostrado presentar dos patrones diferentes, el de los ovarios en envejecimiento, con niveles bajos de la hormona antimülleriana, variaciones mínimas de estos y ciclos menstruales más cortos, y el de los ovarios más jóvenes, con valores altos de la hormona antimülleriana y variaciones significativas en sus niveles a lo largo del ciclo [53].
En la literatura también se han informado hallazgos contradictorios en cuanto a la influencia de la supresión ovárica debido al uso de anticonceptivos orales y el embarazo sobre los niveles séricos de la hormona antimülleriana. La mayoría de estudios han encontrado una disminución entre el $30 \%$ y el $50 \%$ de los niveles de la hormona en la sangre de las mujeres que consumen anticonceptivos orales, los cuales retornan a la normalidad una vez se suspenden [53-55]. En relación con el embarazo, los hallazgos han sido similares a los encontrados con los anticonceptivos orales. Nelson y colaboradores [56] informaron una disminución marcada en los niveles séricos de la hormona antimülleriana durante el segundo y tercer trimestre del embarazo, con una disminución de casi el $50 \%$ hacia el final del embarazo, frente a los niveles en el primer trimestre. Estos hallazgos fueron confirmados por Koninger y colaboradores en 2013 [57].

\section{Utilidad clínica de la hormona antimülleriana en las mujeres}

\section{Hormona antimülleriana como marcador tumoral}

En 1992, la hormona antimülleriana fue identificada como un marcador confiable para el diagnóstico de tumores ováricos de células de la granulosa [58], al ser exclusivamente secretada por estas células en los pequeños folículos en crecimiento. Este tipo de tumores conducen a la elevación de los niveles séricos de la hormona antimülleriana, entre un $76 \%$ y un $96 \%$ de las mujeres que los padecen respecto a las mujeres sanas [59], cuya producción se correlaciona directamente con el tamaño del tumor [60]. 
Además, en las pacientes a quienes se les realizaron mediciones seriadas de la hormona antimülleriana después de la resección del tumoral inicial, la elevación de los niveles precedió a la detección de recurrencia hasta en 16 meses [61]. Por su parte, la hormona antimülleriana demostró ser más sensible y específica que el estradiol para el diagnóstico y seguimiento de los tumores de células de la granulosa de tipo adulto [62], que mantienen una producción de estradiol altamente variable.

En cuanto a los tumores ováricos epiteliales, su origen se ha asociado a los tejidos derivados embriológicamente de los conductos müllerianos que, como se mencionó previamente, son inducidos a regresión por la hormona antimülleriana durante la vida fetal. $A$ partir de esto, varios estudios in vitro han demostrado el papel inhibitorio de la hormona sobre las células epiteliales de cáncer de ovario [63-65], lo que establece el comienzo de un papel más protagónico de la hormona antimülleriana, como posible agente terapéutico o diagnóstico de este tipo de tumores.

\section{Hormona antimülleriana en el síndrome de ovario poliquístico}

El síndrome de ovario poliquístico es la causa más común de infertilidad anovulatoria, que afecta entre el $10 \%$ y el $15 \%$ de las mujeres en edad reproductiva [66]. Actualmente, en varias partes del mundo, el diagnóstico del síndrome de ovario poliquístico se establece, según el consenso de Rotterdam, cuando existen al menos dos de las tres siguientes características: hiperandrogenismo, oligomenorrea y ovarios poliquísticos [57].

La hormona antimülleriana también puede servir como marcador en el diagnóstico del síndrome de ovario poliquístico. El aumento en la producción de la hormona antimülleriana, como ya se mencionó, induce a una disminución en la sensibilidad a la FSH [26], hormona necesaria para el crecimiento de los folículos, lo que contribuye a que aumente el número de los folículos antrales en detrimento de su tamaño, con incremento en el número de pequeños folículos antrales de $2 \mathrm{~mm}$ a $5 \mathrm{~mm}$, productores de más hormona antimülleriana y perturbación en la selección del folículo dominante, característico del síndrome de ovario poliquístico. Tal situación se identifica clínicamente por ciclos de anovulación, que se manifiesta como oligo o amenorrea $[13,67]$. Además, como también se describió, la hormona antimülleriana inhibe la actividad de la aromatasa, lo que conduce a la hiperandrogenemia $[30,31]$, otra característica típica del síndrome de ovario poliquístico.

De igual manera, como ya fue dicho, la secreción de la hormona antimülleriana y sus niveles séricos disminuyen con la edad $[32,33]$; no obstante, en las pacientes con síndrome de ovario poliquístico esta disminución es menos marcada $[68,69]$, lo que indica un envejecimiento ovárico retardado que puede ser explicado por la supresión del crecimiento y de la diferenciación de los folículos primordiales, producto de los altos niveles de la hormona antimülleriana encontrados en las mujeres con síndrome de ovario poliquístico $[13,39,67,70]$.

En las mujeres con síndrome de ovario poliquístico anovulatorio y ovulatorio los niveles de la hormona antimülleriana son 75 y 20 veces, respectivamente, más altos que en las mujeres que no padecen el síndrome [71]; observación que fue confirmada en un estudio del fluido folicular en un grupo de mujeres con este síndrome [72]. La elevación 
de los niveles de hormona antimülleriana en el síndrome de ovario poliquístico refleja la carga de folículos en crecimiento, lo que indica su gran importancia como marcador de la gravedad de la disfunción ovárica y el hiperandrogenismo en las mujeres con síndrome de ovario poliquístico [73].

Gracias a la fuerte participación de la hormona antimülleriana en la fisiopatología del síndrome de ovario poliquístico, se ha abierto la discusión sobre su uso para facilitar el diagnóstico y su inclusión entre los criterios de Rotterdam como un marcador diagnóstico para este síndrome [74-76]. Algunos estudios han planteado la posibilidad de que la hormona antimülleriana pueda reemplazar a la ultrasonografía pélvica en el diagnóstico de este síndrome $[77,78]$, gracias a la fuerte correlación entre los niveles séricos de la hormona antimülleriana y el número de folículos por ovario (medido por esta técnica) [77]; sin embargo, los resultados han sido heterogéneos y no concluyentes. Debido a las numerosas técnicas disponibles para la medición sérica de la hormona antimülleriana, y a la falta de un consenso internacional para sus directrices y punto de corte, su uso como marcador diagnóstico del síndrome de ovario poliquístico no será consolidado hasta que los estudios de estandarización se encuentren disponibles $[3,79]$.

\section{Hormona antimülleriana como marcador de la reserva ovárica}

La hormona antimülleriana refleja el número de folículos preantrales con gran exactitud, por lo que es considerada un marcador de la reserva de ovocitos para la reproducción [13]. Los valores séricos de la hormona antimülleriana se correlacionan fuertemente con el número de folículos maduros cuantificados por ultrasonografía, y con las concentraciones de la hormona en el fluido folicular [70]; además, su determinación en mujeres en edad fértil permite establecer, con mayor sensibilidad y especificidad, la reserva ovárica en comparación con la FSH, el estradiol y la inhibina $\mathrm{B}$ pues, a diferencia de estas, actúa principalmente a nivel paracrino y no participa en los mecanismos de retroalimentación negativa del eje hipotálamo-hipófisis-gonadal [67].

Son numerosos los estudios que demuestran que la hormona antimülleriana sérica es notablemente menor o ausente en las mujeres con insuficiencia ovárica sintomática [80-83], caracterizada por irregularidad menstrual o amenorrea asociada al agotamiento de los oocitos, acompañada de bajos niveles de estradiol y elevación de la FSH, cuyo diagnóstico temprano en las adolescentes es cada vez más de mayor importancia, debido a las consecuencias en la salud de quienes la padecen [83]. La hormona antimülleriana está emergiendo como un marcador sérico temprano y preciso para la detección de aquellas mujeres que probablemente desarrollen una disminución de la reserva ovárica, o una insuficiencia ovárica primaria o prematura antes de ser sintomáticas $[83,84]$.

Un estudio realizado por Leader y colaboradores [85], en 5.354 mujeres que acudieron a centros de fertilidad de 30 estados diferentes de Estados Unidos, demostró que en una de cada cinco (20\%) mujeres que presentaban niveles "tranquilizadores» de la FSH (menores que $10 \mathrm{IU} / \mathrm{L}$ ) se encontraban niveles «preocupantes» de la hormona antimülleriana (menor que $0,8 \mathrm{ng} / \mathrm{mL}$ ), indicativos de una baja reserva ovárica. Por lo tanto, la hormona antimülleriana sérica puede ser un recurso importante para identificar, de forma rutinaria, a las mujeres en riesgo 
de una disminución acelerada de la reserva ovárica [84].

\section{Hormona antimülleriana en la reproducción asistida}

El envejecimiento ovárico en las mujeres que son sometidas a tratamiento para la infertilidad se caracteriza por una disminución de la respuesta ovárica a la administración de gonadotropina exógena, y a malos resultados del embarazo, lo que hace importante la evaluación de la reserva ovárica de las pacientes antes de ingresar a los programas de fertilización in vitro [67]. De esta manera, la hormona antimülleriana también se ha establecido como el mejor marcador pronóstico de la respuesta ovárica durante los ciclos de fecundación in vitro, definida como el número de ovocitos recuperados durante la aspiración folicular o el número de ciclos interrumpidos debido a la ausencia o la alteración del crecimiento folicular, especialmente cuando se utiliza un único marcador de forma independiente [86-88]. En comparación con el recuento de folículos antrales, la medición de las concentraciones de hormona antimülleriana tiene la capacidad de predecir, adecuadamente y de forma equiparable, la mala respuesta a la hiperestimulación ovárica en los ciclos de fecundación in vitro [89].

Por otra parte, los niveles basales de la hormona antimülleriana se encuentran incrementados en las mujeres con síndrome de hiperestimulación ovárica, en comparación con aquellas con respuesta normal a la inducción de ovulación múltiple con gonadotropinas humanas; por lo que podría servir como un marcador para la identificación de las pacientes en riesgo de desarrollar este síndrome [90]. Más adelante,
Nelson y colaboradores [91], en un estudio prospectivo, encontraron que la tasa de embarazos después de la fecundación in vitro aumenta cuando los niveles de la hormona antimülleriana son altos antes de la inducción de la ovulación con gonadotropinas humanas, lo cual podría atribuirse al mayor número de ovocitos recuperados en las mujeres con niveles altos de la hormona antimülleriana [92]. Así mismo, se ha demostrado que las tasas de embarazo en los ciclos de fecundación in vitro están fuertemente asociadas con los niveles de la hormona antimülleriana en el líquido folicular $[93,94]$.

\section{Hormona antimülleriana como marcador del envejecimiento ovárico}

El número de folículos primordiales disminuyen con la edad, y para la menopausia están prácticamente agotados. Con la edad los niveles séricos de la hormona antimülleriana se reducen, lo que refleja la disminución en el número de folículos ováricos [95-97]; incluso, con una mayor correlación que la inhibina B, la FSH y el estradiol [96], por lo que ha sido aceptada como un marcador del envejecimiento ovárico.

La menopausia es un evento difícil de predecir y no existe una prueba que pueda informar de manera precisa su inicio [84]; sin embargo, hace algunos años la hormona antimülleriana en suero se describió como un marcador para la estadificación menopáusica cuya disminución se presenta antes que otros hallazgos, como el aumento de la FSH o la menstruación irregular [98], y que predice, con mayor precisión, el tiempo de aparición de la menopausia que la edad de inicio de la menopausia en la madre [99]. 
Los modelos para predecir la edad menopáusica, en los que se utiliza la hormona antimülleriana, han demostrado que discriminan bien entre la probabilidad de un inicio temprano y uno tardío de la menopausia [100]. No obstante, la interpretación clínica continúa siendo cualitativa: las mujeres con niveles de la hormona antimülleriana muy bajos para su edad son más propensas a entrar en la menopausia más temprano, y aquellas con niveles muy altos para su edad tienen un inicio de la menopausia más tardío [84].

\section{Hormona antimülleriana como marcador de daño ovárico en mujeres expuestas a quimio o radioterapia}

Las terapias contra el cáncer, particularmente la radioterapia pélvica y algunos agentes quimioterapéuticos, tienen un efecto gonadotóxico que lleva a la pérdida de la reserva de los folículos ováricos en crecimiento. Dependiendo del grado del daño ovárico, la mayoría de las pacientes que sobreviven al cáncer pueden experimentar insuficiencia ovárica primaria durante el tratamiento, o poco tiempo después de haberlo terminado; no obstante, no existe, en la actualidad, un método confiable para predecir qué tan pronto ocurrirá. Dado que la hormona antimülleriana es útil para la evaluación de la reserva ovárica podría ser considerada también un marcador importante en el periodo de seguimiento para predecir cuáles mujeres están en riesgo de desarrollar insuficiencia ovárica primaria y, en consecuencia, ser candidatas a asesoramiento sobre fertilidad, y después de finalizado el tratamiento para determinar el efecto de la quimioterapia a largo plazo sobre la función ovárica [82].

La reducción de las concentraciones de hormona antimülleriana ha sido informada como un marcador fiable para la evaluación del deterioro de los ovarios, causado por la quimioterapia o radioterapia [101,102]. En un estudio realizado por Brougham y colaboradores [103], en el que se midieron los niveles de la hormona antimülleriana prospectivamente, desde el diagnóstico hasta el seguimiento seis meses después de la finalización del tratamiento, en una cohorte de niñas prepuberales y puberales con cáncer, se confirmó que la hormona antimülleriana disminuye progresivamente durante la quimioterapia, llegando a ser incluso indetectable en ciertos casos, y que se recupera una vez terminado el tratamiento. Este estudio confirma que los niveles de la hormona antimülleriana reflejan el daño ovárico después del tratamiento contra el cáncer. De manera similar, Lunsford y colaboradores [104] demostraron, en niñas que superaron el cáncer, que la medición de la FSH en suero es un método subóptimo para la identificación de aquellas en riesgo de pubertad tardía, en comparación con la cuantificación de la hormona antimülleriana, lo que hace a esta última una herramienta útil para la evaluación de la reserva ovárica en esta población.

Los resultados de Dillon y colaboradores [105] mostraron que las adolescentes y las mujeres adultas jóvenes con cáncer, que presentan mediciones bajas de la hormona antimülleriana antes del tratamiento, tienen tasas más bajas de recuperación de sus niveles, lo que sugiere que el tamaño inicial de la reserva folicular primordial predice la función ovárica restante después del tratamiento. De igual manera, Anderson y colaboradores [106] encontraron que en las mujeres adultas los niveles bajos de la hormona antimülleriana se relacionan con una mayor probabilidad de desarrollar amenorrea después de la quimioterapia, por lo que se considera que las mediciones de la 
hormona pretratamiento pueden ayudar a la toma de decisiones respecto al tipo de terapia y las estrategias para la preservación de la fertilidad.

\section{Hormona antimülleriana como marcador del daño ovárico en mujeres expuestas a cirugía}

La cirugía ovárica conduce a mayor riesgo de daño ovárico y una reducción de la reserva de folículos restantes. La hormona antimülleriana, al ser un marcador de la reserva ovárica, ha sido usada ampliamente para evaluar el daño ovárico después de la cirugía [4]. Específicamente, se ha reportado que la escisión quirúrgica por laparoscopia de endometriomas resulta en una disminución inmediata y sostenida en el tiempo de los niveles séricos de la hormona antimülleriana, indicativo de una reducción posoperatoria en la reserva ovárica [107]. Dos metanálisis publicados en 2012, uno conformado por ocho estudios prospectivos de cohortes que incluían un total de 237 pacientes con endometriomas [108] y el otro por 11 estudios diferentes [109], confirmaron el daño asociado a la cirugía sobre la reserva ovárica después de la extirpación de los endometriomas, evidenciado por la reducción en los niveles séricos de la hormona antimülleriana luego de la intervención.

En cuanto a la salpingectomía, hay razones para creer que también afecta a los ovarios, debido a la estrecha asociación anatómica entre estos y las trompas de Falopio; sin embargo, solo unos pocos estudios han utilizado las mediciones séricas de la hormona antimülleriana para evaluar el daño ovárico después del procedimiento, donde algunos reportan niveles disminuidos en las mujeres salpingectomizadas [110] y en otros no se encuentra impacto alguno sobre la reserva ovárica [111].

\section{Hormona antimülleriana en la obesidad}

La obesidad afecta a una quinta parte de la población femenina, $18,3 \%$ de ellas en edad reproductiva (16 a 44 años) [112]. En las mujeres obesas la prevalencia de la infertilidad es mayor debido a la disminución de la reserva ovárica y a la disfunción folicular [113]. Aunque el mecanismo subyacente no está bien entendido, se ha planteado la hipótesis de que los bajos niveles de adiponectina (adipocitoquina) estimulan la actividad de la aromatasa en el ovario [114] y, como resultado, disminuye la producción de la hormona antimülleriana, que refleja la disfunción de la foliculogénesis [74].

Un estudio realizado por Piouka y colaboradores [115] demostró que los niveles de la hormona antimülleriana son menores en las mujeres con sobrepeso y obesidad que sufrían del síndrome de ovario poliquístico, en comparación con las mujeres de peso normal que también padecen este síndrome y las mujeres controles sanos, lo cual podría atribuirse a los niveles más bajos de la hormona luteinizante observados en las mujeres obesas y con sobrepeso debido a la mayor aromatización periférica de los andrógenos a los estrógenos en el tejido adiposo [116]. Lo anterior, se encuentra apoyado por un estudio in vitro que muestra que la adición de hormona luteinizante a los cultivos de células de la granulosa, provenientes de mujeres con síndrome de ovario poliquístico, triplica la cantidad de hormona antimülleriana producida [71].

Por su parte, en el estudio de Mehri y colaboradores [117] se evaluaron los niveles de la hormona antimülleriana en mujeres obesas de edad variable, antes y después de la realización de la cirugía bariátrica, donde, a pesar 
del pequeño tamaño de la muestra y el corto periodo de seguimiento, se encontró una reducción significativa de la hormona antimülleriana después de la disminución del índice de masa corporal en el grupo de mujeres jóvenes (menores de 35 años), pero no en los grupos de más edad. Otros estudios también han encontrado niveles más bajos de la hormona antimülleriana en las mujeres obesas, respecto a las no obesas que se encuentran en su último año reproductivo (35 a 49 años) [37] y en aquellas usuarias de anticonceptivos orales [38].

En otro estudio realizado por Moran y colaboradores, que incluyó un pequeño número de mujeres obesas con síndrome de ovario poliquístico que siguieron un programa de pérdida de peso y mantenimiento de seis meses, se demostró que las mujeres con reducción de peso y mejoría del ciclo menstrual eran aquellas que tenían niveles de la hormona antimülleriana significativamente menores antes del tratamiento, mientras que en las mujeres que tenían niveles más altos de hormona antimülleriana, antes de la pérdida de peso, los ciclos menstruales no presentaron mejoría. Con base en estos hallazgos, los autores recomiendan la medición de la hormona antimülleriana en las mujeres con sobrepeso $u$ obesidad y síndrome de ovario poliquístico antes de la implementación del programa de pérdida de peso, como una herramienta pronóstica de la mejora del ciclo menstrual.

En contraposición, los mismos autores, posteriormente, evaluaron el impacto de la pérdida de peso en las concentraciones de la hormona antimülleriana en mujeres con sobrepeso u obesidad con síndrome de ovario poliquístico y alteraciones reproductivas, sometidas a un programa de 20 semanas de dieta hipocalórica, donde encontraron que los niveles de la hormona antimülleriana no se alteran significativamente en el grupo de mujeres que perdieron peso, ni en las que no respondieron a la dieta, aunque nuevamente aquellas con niveles bajos de la hormona antimülleriana antes del tratamiento y con mayor pérdida de peso fueron las que presentaron mejoría en la función reproductiva [118].

\section{Medición de los niveles séricos de la hormoma antimülleriana}

\section{Técnicas disponibles para la medición de la hormona antimülleriana}

La medición de la hormona antimülleriana fue reportada por primera vez en 1990, con el desarrollo de tres ensayos inmunoabsorbentes ligados a enzimas (ELISA; del inglés, Enzyme-Linked Immuno-Sorbent Assay) [119-121] para evaluar la función testicular durante la infancia; momento en que las concentraciones séricas son mucho más altas que en las mujeres. De estos ensayos, los desarrollados por Hudson y colaboradores [120] y Baker y colaboradores [119] no eran lo suficientemente sensibles para detectar las concentraciones de la hormona antimülleriana en muestras de suero de mujeres, mientras que el ensayo desarrollado por Josso y colaboradores [121], el más sensible de todos, fue posteriormente modificado por Carre-Eusebe y colaboradores [122] a una ELISA tipo sándwich que utilizaba anticuerpos mono y policlonales dirigidos contra la hormona antimülleriana recombinante humana (rhAMH), y que reconocen la prorregión y la región madura de la hormona antimülleriana, lo que aumentó la sensibilidad del ensayo. Más tarde, Long y 
colaboradores [123] le hicieron una mejora importante a la prueba mediante el uso de dos tipos de anticuerpos monoclonales, que aumentaron aún más la sensibilidad.

En 2005, se desarrolló una ELISA más sensible y específica que usaba un par de anticuerpos de captura y detección contra la hormona antimülleriana [124], los cuales permitieron medir sus concentraciones en suero, líquido folicular y líquido seminal, e investigar el rol de la hormona antimülleriana en los sistemas reproductivos de los hombres y mujeres. Anteriormente se realizaban dos tipos de ELISA para la medición de la hormona antimülleriana, el Immunotech (IOT; Beckman-Coulter, California, Estados Unidos) y el Diagnosctic Systems Lab (DSL; Diagnostic Systems Laboratories Inc., Texas, Estados Unidos) que utilizan diferentes pares de anticuerpos contra la hormona antimülleriana y estándares de calibración, lo que lleva a que los valores reportados de la hormona, por ambos ensayos, difieran de manera significativa; usualmente cuatro veces más bajos con el ensayo Diagnosctic Systems Lab respecto al Immunotech [125].

Hace pocos años, después de que Beckman Coulter adquiriera a Diagnostic Systems Laboratories, se desarrolló el ensayo Gen II para la hormona antimülleriana, el cual combina los pares de anticuerpos del ensayo DSL, que reconocen la región madura y, por tanto, son más específicos y evitan que los niveles de la hormona se vean afectados por la proteólisis en la muestra, y los estándares de calibración del Immunotech [126,127], lo que permite que tenga un desempeño esencialmente idéntico al del ensayo original [126]. Recientemente, nuevos estuches para medir la hormona antimülleriana han aparecido y se encuentran disponibles en el mercado, entre los que se incluyen el estuche $\mathrm{AMH} /$
MIS ELISA Ultrasensible de Ansh Labs (Texas, Estados Unidos) [128], el inmunoensayo automatizado Access AMH de Beckman Coulter (California, Estados Unidos) [129] y el inmunoensayo de electroquimioluminiscencia Elecsys ${ }^{\circledR}$ AMH de Roche Diagnostics International Ltd (Risch-Rotkreuz, Suiza) [130], los cuales han mostrado una buena correlación entre ellos y con la prueba Gen II, a pesar de presentar algunas diferencias en cuanto a los calibradores [131].

\section{Prueba AMH/MIS ELISA Ultrasensible para la medición de la hormona antimülleriana}

Actualmente, el Laboratorio Clínico Hematológico (Medellín, Colombia) cuenta con el estuche AMH/MIS ELISA Ultrasensible de Ansh Labs para la medición de la hormona antimülleriana que, como se mencionó previamente, consiste en un ensayo inmunoabsorbente ligado a enzimas (ELISA) de tipo sándwich cuantitativo de tres pasos que permite la medición cuantitativa de la hormona antimülleriana en suero y otros fluidos humanos [128].

\section{Condiciones preanalíticas}

La medición de los niveles de la hormona antimülleriana no tiene establecidas condiciones preanalíticas especiales, se recomienda seguir las propias del laboratorio que realice la prueba, por ejemplo, que el paciente se encuentre en ayunas para mejor estandarización de la prueba. El tipo de muestra preferible para la determinación es suero recolectado en tubos secos (tapa roja) o con gel separador (tapa amarilla) en las primeras horas de la mañana, aunque también puede ser medida en muestras de plasma con heparina de litio y otros fluidos biológicos. Las muestras se deben conservar a $4{ }^{\circ} \mathrm{C}$ hasta por 24 horas para su procesamiento, de lo con- 
trario se deben almacenar a $-20{ }^{\circ} \mathrm{C} 0-80{ }^{\circ} \mathrm{C}$ para evitar la pérdida de bioactividad y una posible contaminación [128].

\section{Fundamento de la prueba}

En el primer paso, se dispensan los calibradores, los controles y las muestras en los pocillos de microtitulación recubiertos con anticuerpos de captura anti-hormona antimülleriana, a los que se va a unir la hormona antimülleriana presente en estos. En el segundo paso, se adicionan los anticuerpos biotinilados anti-hormona antimülleriana que se van a unir al complejo antígenoanticuerpo formado en la fase sólida de los pocillos durante el primer paso. En la tercera etapa se incluye en los pocillos la solución de estreptavidina conjugada con peroxidasa de rábano picante (SHRP), la cual se une al conjugado anticuerpo-biotina previamente incorporado al complejo antígeno-anticuerpo de la fase sólida (véase figura 5) [128].

Una vez finalizadas las tres etapas, separadas entre ellas por diferentes tiempos y condiciones de incubación y lavado, se adiciona a los pocillos la solución del sustrato cromogénico de tetrametilbencidina (TMB) y, luego de una incubación final, una solución ácida de parada (véase figura 5). Finalmente, el complejo anticuerpo-antígeno-conjugado de biotina-SHRP, fijado al pocillo, es detectado por la reacción enzima-sustrato, donde el grado de transformación enzimática del sustrato se determina por la doble medición de la absorbancia a una longitud de onda de $450 \mathrm{~nm}$ (como filtro de ensayo primario) y de $630 \mathrm{~nm}$ (como filtro de referencia). La absorbancia medida es directamente proporcional a la concentración de hormona antimülleriana presente en las muestras, los controles y los calibradores [128].

\section{Valores de referencia de la prueba}

Actualmente, no se ha establecido un rango de referencia universal para la hormona antimülleriana. Cada laboratorio debe plantear sus propios valores de acuerdo con el método usado y la población de estudio, teniendo en cuenta que los niveles de la hormona antimülleriana varían según la edad y el sexo. En el estuche AMH/ MIS ELISA Ultrasensible los valores de la hormona antimülleriana se expresan en $\mathrm{ng} / \mathrm{mL}$ y en las mujeres sanas se han establecido como normales, según la edad, los siguientes [128]:

Menores de 2 meses: $<0,02 \mathrm{ng} / \mathrm{mL}$ a $0,49 \mathrm{ng} / \mathrm{mL}$

Menores de 10 años: $0,05 \mathrm{ng} / \mathrm{mL}$ a $10,40 \mathrm{ng} / \mathrm{mL}$

Entre 11 y 20 años: 0,62 ng/mL a $11,00 \mathrm{ng} / \mathrm{mL}$

Entre 21 y 30 años: $<0,02 \mathrm{ng} / \mathrm{mL}$ a $10,39 \mathrm{ng} / \mathrm{mL}$

Entre 31 y 40 años: 0,14 ng/mL a $10,40 \mathrm{ng} / \mathrm{mL}$

Entre 41 y 50 años: $<0,02 \mathrm{ng} / \mathrm{mL}$ a $6,35 \mathrm{ng} / \mathrm{mL}$

Mayores de 51 años: $<0,02 \mathrm{ng} / \mathrm{mL}$ a $0,39 \mathrm{ng} / \mathrm{mL}$

\section{Interpretación de resultados}

Al igual que todas las pruebas de laboratorio, la medición de la hormona antimülleriana por sí sola no es suficiente para establecer un diagnóstico particular en las mujeres a las que se les determina. Los resultados obtenidos se deben interpretar a la luz de los 


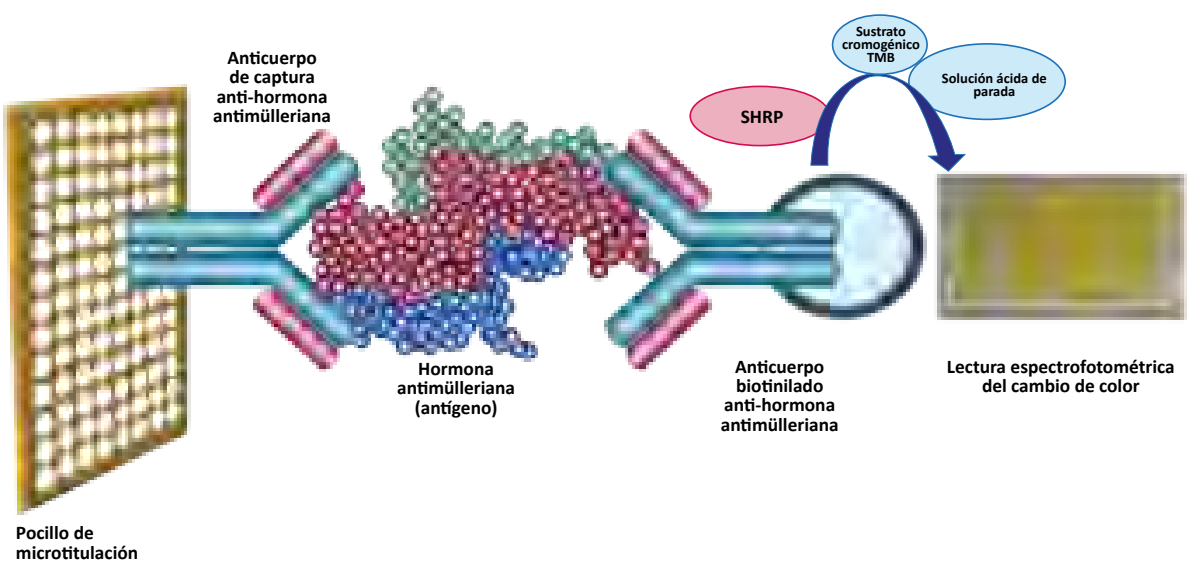

Figura 5. Metodología del estuche AMH/MIS ELISA Ultrasensible de Ansh Labs (Texas, Estados Unidos). SHRP: estreptavidina conjugada con peroxidasa de rábano picante. TMB: tetrametilbencidina. Tomado y modificado de «Development of a Well Characterized Ultra-Sensitive Human Anti-Müllerian Hormone (AMH) ELISA» por A. Kumar y colaboradores, 2013, póster presentado en: American Association for Clinical Chemistry [126].

hallazgos clínicos y los resultados de otras pruebas pertinentes, como la ultrasonografía ovárica (recuento folicular antral), en los casos de evaluación de la fertilidad, los niveles de la hormona FSH y la inhibina B para los estudios de fertilidad, y la inhibina A y la inhibina $B$ para el tratamiento tumoral. De igual manera, se debe considerar que los niveles elevados de la hormona antimülleriana no son específicos de neoplasias malignas y su análisis no se debe utilizar, exclusivamente, para diagnosticar o excluir un tumor ovárico secretador de la hormona [132].

Como ya se mencionó, en las mujeres menopáusicas [98,99], con insuficiencia ovárica primaria por cualquier causa [80-83] o después de haberse sometido a quimioterapia $[101,102]$, se presentan niveles muy bajos de la hormona antimülleriana, incluso por debajo del límite de detección de la prueba. Por su parte, en las pacientes con síndrome de ovario poliquístico las concentraciones de la hormona antimülleria- na pueden ser dos a cinco veces mayores que los valores de referencia apropiados para la edad, lo cual predice la presencia de ciclos anovulatorios e irregulares [71]. En cuanto a las mujeres con masas ováricas, los niveles elevados de hormona antimülleriana pueden ser indicativos de un tumor de células de la granulosa, donde la reducción en el tiempo de los niveles de la hormona es indicativa de éxito en el tratamiento, mientras que el aumento sugiere recidiva o progresión [58-61].

Por otro lado, para la predicción de la respuesta a la fecundación in vitro todavía no se han establecido las concentraciones óptimas de la hormona antimülleriana; no obstante, dependiendo de la edad de la paciente, los niveles bajos pueden ser indicativos de una posible falla en la estimulación ovárica, mientras que las concentraciones séricas aumentadas pueden indicar una hiperestimulación ovárica [89,90]. 


\section{Características analíticas de la prueba}

El estuche AMH/MIS ELISA Ultrasensible, de acuerdo con el inserto del producto, presenta un límite de detección de 0,023 ng/ $\mathrm{mL}$, un rango de detección de $0,06 \mathrm{ng} / \mathrm{mL}$ a $11,6 \mathrm{ng} / \mathrm{mL}$ y coeficientes de variación intra e interensayo para concentraciones entre $0,35 \mathrm{ng} / \mathrm{mL}$ y $1,85 \mathrm{ng} / \mathrm{mL}$ menores que $4,0 \%$ y $4,8 \%$, respectivamente. Además, el par de anticuerpos monoclonales incluidos son específicos de la hormona antimülleriana humana, por lo que no presentan reacción cruzada con la hormona de otras especies u otras proteínas similares estructuralmente. El uso de muestras lipémicas, hemolizadas o ictéricas, al igual que los ciclos repetitivos de congelación y descongelación de las muestras no es recomendable. Como interferentes solo se registran los anticuerpos heterófilos y la contaminación visible de la muestra, los cuales pueden producir resultados falsamente altos [128].

En cuanto el desempeño de este método para la determinación de los niveles de la hormona antimülleriana, Li y colaboradores evaluaron 178 muestras de suero humano de mujeres, donde encontraron que el estuche AMH/MIS ELISA Ultrasensible, para concentraciones de la hormona antimülleriana entre $1,3 \mathrm{ng} / \mathrm{mL}$ y $11,2 \mathrm{ng} / \mathrm{mL}$, presentaba coeficientes de variación intraensayo e interensayo entre $1,4 \%$ y $5,4 \%$ y entre $6,2 \%$ y $13,5 \%$, respectivamente; además, altos niveles de linealidad, con un coeficiente de correlación de Spearman entre los valores esperados y los obtenidos de 0,997, y un porcentaje de recuperación del $81 \%$ al $99 \%$. Igualmente, hallaron que este método logra discriminar adecuadamente los sueros de las mujeres con síndrome de ovario poliquístico de los de las mujeres ovulato- rias normales [131]. Previamente, Welsh y colaborares habían informado un desempeño similar de la prueba en 193 sueros de mujeres [133]. Estos hallazgos, en conjunto, demuestran que el estuche AMH/MIS ELISA Ultrasensible es un método válido y adecuado para su uso clínico.

\section{Conclusiones}

La hormona antimülleriana, inicialmente considerada como una hormona masculina, ha surgido como una herramienta invaluable para la evaluación de la función ovárica en la infancia, la adolescencia y la adultez. La hormona antimülleriana sérica es un marcador autónomo, oportuno y fiable que refleja la actividad ovárica, gracias a su fuerte correlación con el número de folículos, a su no dependencia del operador y a la predicción exacta de la vida reproductiva $[3,92]$.

Los niveles de la hormona antimülleriana reflejan, con alta precisión, la reserva de folículos ováricos, como se ha demostrado en numerosos estudios [134-138]. Por lo tanto, su evaluación tiene gran importancia clínica en la predicción del éxito de los ciclos de fecundación in vitro [32,89,139,140]. A su vez, sus niveles representan el marcador más sensible para la confirmación de la inevitable disminución del número de folículos primordiales relacionada con el envejecimiento [95-97].

La determinación de la hormona antimülleriana puede ser utilizada también en el diagnóstico o el seguimiento de las mujeres con tumores de origen celular de granulosa, y como un marcador complementario del síndrome de ovario poliquístico, en los casos en que el examen ultrasonográfico de los ovarios no sea factible $[77,78]$. Por último, la relación, recientemente revelada, entre la hormona antimülleriana y la obesi- 
dad $[37,115,117]$ establece como objetivo de investigación futura la determinación de los mecanismos patogénicos que vinculan la obesidad y la disfunción gonadal.

Actualmente, no se dispone de un método estándar de referencia ni de una norma internacional que unifique el proceso de medición de la hormona antimülleriana de forma rutinaria, a través de los diferentes métodos disponibles, y que permita establecer los valores de referencia universales de esta hormona, con una significancia clínica para las diversas aplicaciones que posee [131,133]. No obstante, el estuche AMH/ MIS ELISA Ultrasensible, ajustado a las condiciones de cada laboratorio y población de estudio, representa una herramienta útil para la cuantificación de los niveles de la hormona antimülleriana, que ha demostrado buen desempeño y validez, y que se encuentra disponible en nuestro medio para la medición de la función ovárica en las mujeres, con aplicabilidad clínica.

\section{Bibliografía}

1. Josso N, Rey RA, Picard JY. Anti-müllerian hormone: a valuable addition to the toolbox of the pediatric endocrinologist. Int J Endocrinol 2013; 2013: 674105.

2. Edelsztein NY, Grinspon RP, Schteingart HF, Rey RA. Anti-müllerian hormone as a marker of steroid and gonadotropin action in the testis of children and adolescents with disorders of the gonadal axis. Int J Pediatr Endocrinol 2016; 2016: 20.

3. Dewailly D, Andersen CY, Balen A, Broekmans F, Dilaver N, Fanchin R, et al. The physiology and clinical utility of Anti-müllerian hormone in women. Hum Reprod Update 2014 ; 20: 370-385.

4. Grynnerup AG, Lindhard A, Sorensen S. Recent prog ress in the utility of Anti-müllerian hormone in female infertility. Curr Opin Obstet Gynecol 2014; 26: 162167.

5. Omabe M, Ezeani M, Martin O. Clinical Utilities of Anti-müllerian Hormone. Sch J App Med Sci 2013; 1: 606-618.

6. Achermann JC, Hughes IA. Trastornos pediátricos del desarrollo sexual. En: Melmed S, Polonsky K, Larsen PR, Kronenberg $\mathrm{H}$, eds. Williams Tratado de endocrinología + ExpertConsult (ed 13a). Barcelona, España: Elsevier; 2017: 893-963.

7. Eggers S, Ohnesorg T, Sinclair A. Genetic regulation of mammalian gonad development. Nat Rev Endocrinol 2014; 10: 673-683.

8. Smith P, Wilhelm D, Rodgers RJ. Development of mammalian ovary. J Endocrinol 2014; 221: R145-161.

9. Fowler PA, Anderson RA, Saunders PT, Kinnell H, Mason JI, Evans DB, et al. Development of steroid signaling pathways during primordial follicle formation in the human fetal ovary. J Clin Endocrinol Metab 2011; 96: 1754-1762.

10. Feng CW, Bowles J, Koopman P. Control of mammalian germ cell entry into meiosis. Mol Cell Endocrinol 2014; 382: 488-497.

11. Eggers S, Ohnesorg T, Sinclair A. Genetic regulation of

mammalian gonad development. Nat Rev Endocrinol 2014; 10: 673-683.

12. Mullen RD, Behringer RR. Molecular genetics of Müllerian duct formation, regression and differentiation. Sex Dev 2014; 8: 281-296.

13. Hampl R, Snajderova $\mathbf{M}$, Mardesic T. Antimüllerian hormone $(\mathrm{AMH})$ not only a marker for prediction of ovarian reserve. Physiol Res 2011; 60: 217-223.

14. La Marca A, Volpe A. Anti-müllerian hormone (AMH) in female reproduction: is measurement of circulating $\mathrm{AMH}$ a useful tool? Clin Endocrinol (Oxf) 2006; 64: 603-610.

15. di Clemente $\mathbf{N}$, Jamin SP, Lugovskoy A, Carmillo P, Ehrenfels $\mathbf{C}$, Picard JY, et al. Processing of Anti-müllerian hormone regulates receptor activation by a mechanism distinct from TGF-beta. Mol Endocrinol 2010; 24: 2193-2206.

16. Lindhardt Johansen $M$, Hagen $C P$, Johannsen $T H$, Main KM, Picard JY, Jorgensen A, et al. Anti-müllerian hormone and its clinical use in pediatrics with special emphasis on disorders of sex development. Int J Endocrinol 2013; 2013: 198698.

17. Rey RA, Grinspon RP. Normal male sexual differentiation and aetiology of disorders of sex development. Best Pract Res Clin Endocrinol Metab 2011; 25: 221238.

18. Hagen CP, Aksglaede L, Sorensen K, Mouritsen A, Andersson AM, Petersen JH, et al. Individual serum levels of Anti-müllerian hormone in healthy girls persist through childhood and adolescence: a longitudinal cohort study. Hum Reprod 2012; 27: 861-866.

19. Lashen H, Dunger DB, Ness A, Ong KK. Peripubertal changes in circulating antimüllerian hormone levels in girls. Fertil Steril 2013; 99: 2071-2075.

20. Wallace $\mathbf{W H}$, Kelsey TW. Human ovarian reserve from conception to the menopause. PLoS One 2010; 5: e8772. 
21. Hansen KR, Hodnett GM, Knowlton N, Craig LB. Correlation of ovarian reserve tests with histologically determined primordial follicle number. Fertil Steril 2011 95: 170-175.

22. Dumont A, Robin G, Catteau-Jonard S, Dewailly D. Role of Anti-müllerian Hormone in pathophysiology, diagnosis and treatment of Polycystic Ovary Syndrome: a review. Reprod Biol Endocrinol 2015; 13: 137.

23. La Marca A, Broekmans FJ, Volpe A, Fauser BC, MackIon NS, Table ESIGfRE--AR. Anti-müllerian hormone (AMH): what do we still need to know? Hum Reprod 2009; 24: 2264-2275.

24. Andersen CY, Schmidt KT, Kristensen SG, Rosendahl M, Byskov AG, Ernst E. Concentrations of $\mathrm{AMH}$ and inhibin-B in relation to follicular diameter in normal human small antral follicles. Hum Reprod 2010; 25: 1282-1287.

25. Jeppesen JV, Anderson RA, Kelsey TW, Christiansen SL, Kristensen SG, Jayaprakasan K, et al. Which follicles make the most Anti-müllerian hormone in humans? Evidence for an abrupt decline in AMH production at the time of follicle selection. Mol Hum Reprod 2013; 19: 519-527.

26. Durlinger AL, Gruijters MJ, Kramer P, Karels B, Kumar TR, Matzuk MM, et al. Anti-müllerian hormone attenuates the effects of FSH on follicle development in the mouse ovary. Endocrinology 2001; 142: 4891-4899.

27. Grynberg M, Pierre A, Rey R, Leclerc A, Arouche N, Hesters $L$, et al. Differential regulation of ovarian Anti-müllerian hormone (AMH) by estradiol through alpha- and beta-estrogen receptors. J Clin Endocrinol Metab 2012; 97: E1649-1657.

28. Durlinger AL, Kramer $\mathbf{P}$, Karels $\mathbf{B}$, de Jong FH, Uilenbroek JT, Grootegoed JA, et al. Control of primordial follicle recruitment by Anti-müllerian hormone in the mouse ovary. Endocrinology 1999; 140: 5789-5796.

29. Visser JA, Durlinger AL, Peters IJ, van den Heuvel ER, Rose UM, Kramer P, et al. Increased oocyte degeneration and follicular atresia during the estrous cycle in Anti-müllerian hormone null mice. Endocrinology 2007; 148: 2301-2308.

30. Grossman MP, Nakajima ST, Fallat ME, Siow Y. Müllerian-inhibiting substance inhibits cytochrome P450 aromatase activity in human granulosa lutein cell culture. Fertil Steril 2008; 89: 1364-1370.

31. Nielsen ME, Rasmussen IA, Kristensen SG, Christensen ST, Mollgard K, Wreford Andersen E, et al. In human granulosa cells from small antral follicles, androgen receptor mRNA and androgen levels in follicular fluid correlate with FSH receptor mRNA. Mol Hum Reprod 2011; 17: 63-70.

32. La Marca A, Nelson SM, Sighinolfi G, Manno M, Baraldi E, Roli L, et al. Anti-müllerian hormone-based prediction model for a live birth in assisted reproduction. Reprod Biomed Online 2011; 22: 341-349.

33. Almog B, Shehata F, Suissa S, Holzer H, Shalom-Paz E, La Marca A, et al. Age-related normograms of serum antimüllerian hormone levels in a population of infer- tile women: a multicenter study. Fertil Steril 2011; 95 : 2359-2363, 2363 e2351.

34. Gougeon A. Ovarian follicular growth in humans: ovarian ageing and population of growing follicles. Maturitas 1998; 30: 137-142.

35. Seifer DB, Golub ET, Lambert-Messerlian G, Benning L, Anastos K, Watts DH, et al. Variations in serum müllerian inhibiting substance between white, black, and Hispanic women. Fertil Steril 2009; 92: 1674-1678.

36. Schuh-Huerta SM, Johnson NA, Rosen MP, Sternfeld B, Cedars MI, Reijo Pera RA. Genetic variants and environmental factors associated with hormonal markers of ovarian reserve in Caucasian and African American women. Hum Reprod 2012; 27: 594-608.

37. Freeman EW, Gracia CR, Sammel MD, Lin H, Lim LC Strauss JF, 3rd. Association of Anti-müllerian hormone levels with obesity in late reproductive-age women. Fertil Steril 2007; 87: 101-106.

38. Steiner AZ, Stanczyk FZ, Patel S, Edelman A. Antimüllerian hormone and obesity: insights in oral contraceptive users. Contraception 2010; 81: 245-248.

39. Park AS, Lawson MA, Chuan SS, Oberfield SE, Hoeger KM, Witchel SF, et al. Serum Anti-müllerian hormone concentrations are elevated in oligomenorrheic girls without evidence of hyperandrogenism. J Clin Endocrinol Metab 2010; 95: 1786-1792.

40. Halawaty S, ElKattan E, Azab H, ElGhamry N, Al-Inany H. Effect of obesity on parameters of ovarian reserve in premenopausal women. J Obstet Gynaecol Can 2010; 32: 687-690.

41. Skalba P, Cygal A, Madej P, Dabkowska-Huc A, Sikora J, Martirosian G, et al. Is the plasma Anti-müllerian hormone (AMH) level associated with body weight and metabolic, and hormonal disturbances in women with and without polycystic ovary syndrome? Eur J Obstet Gynecol Reprod Biol 2011; 158: 254-259.

42. La Marca A, Papaleo E, Grisendi V, Argento C, Giulini S, Volpe A. Development of a nomogram based on markers of ovarian reserve for the individualisation of the follicle-stimulating hormone starting dose in in vitro fertilisation cycles. BJOG 2012; 119: 1171-1179.

43. La Marca A, Spada E, Grisendi V, Argento C, Papaleo E, Milani S, et al. Normal serum Anti-müllerian hormone levels in the general female population and the relationship with reproductive history. Eur J Obstet Gynecol Reprod Biol 2012; 163: 180-184.

44. Overbeek A, Broekmans FJ, Hehenkamp WJ, Wijdeveld ME, van Disseldorp J, van Dulmen-den Broeder E, et al. Intra-cycle fluctuations of Anti-müllerian hormone in normal women with a regular cycle: a re-analysis. Reprod Biomed Online 2012; 24: 664-669.

45. Plante BJ, Cooper GS, Baird DD, Steiner AZ. The impact of smoking on antimüllerian hormone levels in women aged 38 to 50 years. Menopause 2010; 17: 571-576.

46. Freour T, Masson D, Dessolle L, Allaoua D, Dejoie T, Mirallie S, et al. Ovarian reserve and in vitro fertilization cycles outcome according to women smoking status and stimulation regimen. Arch Gynecol Obstet 
2012; 285: 1177-1182.

47. Nardo LG, Christodoulou D, Gould D, Roberts SA, Fitzgerald CT, Laing I. Anti-müllerian hormone levels and antral follicle count in women enrolled in in vitro fertilization cycles: relationship to lifestyle factors, chronological age and reproductive history. Gynecol Endocrinol 2007; 23: 486-493.

48. Dafopoulos A, Dafopoulos K, Georgoulias P, Galazios G, Limberis V, Tsikouras $P$, et al. Smoking and AMH levels in women with normal reproductive history. Arch Gynecol Obstet 2010; 282: 215-219.

49. Waylen AL, Jones GL, Ledger WL. Effect of cigarette smoking upon reproductive hormones in women of reproductive age: a retrospective analysis. Reprod Biomed Online 2010; 20: 861-865.

50. Hehenkamp WJ, Looman CW, Themmen AP, de Jong FH, Te Velde ER, Broekmans FJ. Anti-müllerian hormone levels in the spontaneous menstrual cycle do not show substantial fluctuation. J Clin Endocrinol Metab 2006; 91: 4057-4063.

51. La Marca A, Stabile G, Artenisio AC, Volpe A. Serum Anti-müllerian hormone throughout the human menstrual cycle. Hum Reprod 2006; 21: 3103-3107.

52. Tsepelidis S, Devreker F, Demeestere I, Flahaut A, Gervy C, Englert Y. Stable serum levels of Anti-müllerian hormone during the menstrual cycle: a prospective study in normo-ovulatory women. Hum Reprod 2007; 22: $1837-1840$.

53. Sowers M, McConnell D, Gast K, Zheng H, Nan B, McCarthy JD, et al. Anti-müllerian hormone and inhibin $B$ variability during normal menstrual cycles. Fertil Steril 2010; 94: 1482-1486.

54. Dolleman M, Verschuren WM, Eijkemans MJ, Dolle ME, Jansen EH, Broekmans FJ, et al. Reproductive and lifestyle determinants of Anti-müllerian hormone in a large population-based study. J Clin Endocrinol Metab 2013; 98: 2106-2115.

55. Kallio S, Puurunen J, Ruokonen A, Vaskivuo T, Piltonen T, Tapanainen JS. Antimüllerian hormone levels decrease in women using combined contraception independently of administration route. Fertil Steril 2013; 99: 1305-1310.

56. Nelson SM, Stewart F, Fleming R, Freeman DJ. Longitudinal assessment of antimüllerian hormone during pregnancy-relationship with maternal adiposity, insulin, and adiponectin. Fertil Steril 2010; 93: 1356-1358.

57. Koninger A, Kauth A, Schmidt B, Schmidt M, Yerlikaya G, Kasimir-Bauer $S$, et al. Anti-müllerian-hormone levels during pregnancy and postpartum. Reprod Biol Endocrinol 2013; 11: 60.

58. Gustafson ML, Lee MM, Scully RE, Moncure AC, Hirakawa $\mathrm{T}$, Goodman A, et al. Müllerian inhibiting substance as a marker for ovarian sex-cord tumor. N Engl J Med 1992; 326: 466-471.

59. Rey R, Sabourin JC, Venara M, Long WQ, Jaubert F, Zeller WP, et al. Anti-müllerian hormone is a specific marker of sertoli- and granulosa-cell origin in gonadal tumors. Hum Pathol 2000; 31: 1202-1208.
60. Chang HL, Pahlavan N, Halpern EF, MacLaughlin DT. Serum Müllerian Inhibiting Substance/Anti-müllerian hormone levels in patients with adult granulosa cell tumors directly correlate with aggregate tumor mass as determined by pathology or radiology. Gynecol Oncol 2009; 114: 57-60.

61. Rey RA, Lhomme C, Marcillac I, Lahlou N, Duvillard $\mathrm{P}$, Josso $\mathbf{N}$, et al. Antimüllerian hormone as a serum marker of granulosa cell tumorsof the ovary: comparative study with serum alpha-inhibin and estradiol. Am J Obstet Gynecol 1996; 174: 958-965.

62. Farkkila A, Koskela S, Bryk S, Alfthan H, Butzow $R$, Leminen $A$, et al. The clinical utility of serum Anti-müllerian hormone in the follow-up of ovarian adulttype granulosa cell tumors--A comparative study with inhibin B. Int J Cancer 2015; 137: 1661-1671.

63. Chin TW, Parry RL, Donahoe PK. Human müllerian inhibiting substance inhibits tumor growth in vitro and in vivo. Cancer Res 1991; 51: 2101-2106.

64. Masiakos PT, MacLaughlin DT, Maheswaran S, Teixeira J, Füller AF, Jr., Shah PC, et al. Human ovarian cancer, cell lines, and primary ascites cells express the human Müllerian inhibiting substance (MIS) type II receptor, bind, and are responsive to MIS. Clin Cancer Res 1999; 5: 3488-3499.

65. Ha TU, Segev DL, Barbie D, Masiakos PT, Tran TT, Dombkowski D, et al. Müllerian inhibiting substance inhibits ovarian cell growth through an Rb-independent mechanism. J Biol Chem 2000; 275: 37101-37109.

66. Norman RJ, Dewailly D, Legro RS, Hickey TE. Polycystic ovary syndrome. Lancet 2007; 370: 685-697.

67. Visser JA, de Jong FH, Laven JS, Themmen AP. Anti-müllerian hormone: a new marker for ovarian function. Reproduction 2006; 131: 1-9.

68. Mulders AG, Laven JS, Eijkemans MJ, de Jong FH, Themmen AP, Fauser BC. Changes in Anti-müllerian hormone serum concentrations over time suggest delayed ovarian ageing in normogonadotrophic anovulatory infertility. Hum Reprod 2004; 19: 2036-2042.

69. Piltonen $\mathrm{T}$, Morin-Papunen $\mathrm{L}$, Koivunen R, Perheentupa A, Ruokonen A, Tapanainen JS. Serum Anti-müllerian hormone levels remain high until late reproductive age and decrease during metformin therapy in women with polycystic ovary syndrome. Hum Reprod 2005; 20: 1820-1826.

70. Kaya C, Pabuccu R, Satiroglu H. Serum antimüllerian hormone concentrations on day 3 of the in vitro fertilization stimulation cycle are predictive of the fertilization, implantation, and pregnancy in polycystic ovary syndrome patients undergoing assisted reproduction. Fertil Steril 2010; 94: 2202-2207.

71. Pellatt L, Hanna L, Brincat M, Galea R, Brain H, Whitehead S, et al. Granulosa cell production of Anti-müllerian hormone is increased in polycystic ovaries. J Clin Endocrinol Metab 2007; 92: 240-245.

72. Das M, Gillott DJ, Saridogan E, Djahanbakhch O. Anti-müllerian hormone is increased in follicular fluid from unstimulated ovaries in women with polycystic ovary syndrome. Hum Reprod 2008; 23: 2122-2126. 
73. Bungum L, Franssohn F, Bungum M, Humaidan P, Giwercman A. The circadian variation in Anti-müllerian hormone in patients with polycystic ovary syndrome differs significantly from normally ovulating women. PLoS One 2013; 8: e68223.

74. Jamil Z, Fatima SS, Ahmed K, Malik R. Anti-müllerian Hormone: Above and Beyond Conventional Ovarian Reserve Markers. Dis Markers 2016; 2016: 5246217.

75. Lebkowska A, Kowalska I. Anti-müllerian hormone and polycystic ovary syndrome. Endokrynol Pol 2017; 68: 74-78.

76. Eilertsen TB, Vanky E, Carlsen SM. Anti-müllerian hormone in the diagnosis of polycystic ovary syndrome: can morphologic description be replaced? Hum Reprod 2012; 27: 2494-2502.

77. Dewailly D, Gronier H, Poncelet E, Robin G, Leroy M, Pigny $\mathbf{P}$, et al. Diagnosis of polycystic ovary syndrome (PCOS): revisiting the threshold values of follicle count on ultrasound and of the serum AMH level for the definition of polycystic ovaries. Hum Reprod 2011; 26: 3123-3129.

78. Iliodromiti S, Kelsey TW, Anderson RA, Nelson SM. Can Anti-müllerian hormone predict the diagnosis of polycystic ovary syndrome? A systematic review and meta-analysis of extracted data. J Clin Endocrinol Metab 2013; 98: 3332-3340.

79. Dewailly D, Lujan ME, Carmina E, Cedars MI, Laven J, Norman RJ, et al. Definition and significance of polycystic ovarian morphology: a task force report from the Androgen Excess and Polycystic Ovary Syndrome Society. Hum Reprod Update 2014; 20: 334-352.

80. Kallio S, Aittomaki K, Piltonen T, Veijola R, Liakka A, Vaskivuo TE, et al. Anti-müllerian hormone as a predictor of follicular reserve in ovarian insufficiency: special emphasis on FSH-resistant ovaries. Hum Reprod 2012; 27: 854-860.

81. Chao KC, Ho CH, Shyong WY, Huang CY, Tsai SC, Cheng HY, et al. Anti-müllerian hormone serum level as a predictive marker of ovarian function in Taiwanese women. J Chin Med Assoc 2012; 75: 70-74.

82. Visser JA, Schipper I, Laven JS, Themmen AP. Anti-müllerian hormone: an ovarian reserve marker in primary ovarian insufficiency. Nat Rev Endocrinol 2012; 8: 331-341.

83. Baker VL. Primary ovarian insufficiency in the adolescent. Curr Opin Obstet Gynecol 2013; 25: 375-381.

84. Leader B, Baker VL. Maximizing the clinical utility of antimüllerian hormone testing in women's health. Curr Opin Obstet Gynecol 2014; 26: 226-236.

85. Leader B, Hegde A, Baca Q, Stone K, Lannon B, Seifer DB, et al. High frequency of discordance between antimüllerian hormone and follicle-stimulating hormone levels in serum from estradiol-confirmed days 2 to 4 of the menstrual cycle from 5,354 women in U.S. fertility centers. Fertil Steril 2012; 98: 1037-1042.

86. La Marca A, Sighinolfi G, Radi D, Argento C, Baraldi E, Artenisio AC, et al. Anti-müllerian hormone (AMH) as a predictive marker in assisted reproductive technology (ART). Hum Reprod Update 2010; 16: 113-130.
87. Muttukrishna S, Suharjono H, McGarrigle H, Sathanandan $\mathbf{M}$. Inhibin $B$ and Anti-müllerian hormone: markers of ovarian response in IVF/ICSI patients? BJOG 2004; 111: 1248-1253.

88. Penarrubia J, Fabregues F, Manau D, Creus M, Casals G, Casamitjana R, et al. Basal and stimulation day 5 Anti-müllerian hormone serum concentrations as predictors of ovarian response and pregnancy in assisted reproductive technology cycles stimulated with gonadotropin-releasing hormone agonist--gonadotropin treatment. Hum Reprod 2005; 20: 915-922.

89. Broer SL, Mol B, Dolleman M, Fauser BC, Broekmans FJ. The role of Anti-müllerian hormone assessment in assisted reproductive technology outcome. Curr Opin Obstet Gynecol 2010; 22: 193-201.

90. Nakhuda GS, Chu MC, Wang JG, Sauer MV, Lobo RA. Elevated serum müllerian-inhibiting substance may be a marker for ovarian hyperstimulation syndrome in normal women undergoing in vitro fertilization. Fertil Steril 2006; 85: 1541-1543.

91. Nelson SM, Yates RW, Lyall H, Jamieson M, Traynor I, Gaudoin M, et al. Anti-müllerian hormone-based approach to controlled ovarian stimulation for assisted conception. Hum Reprod 2009; 24: 867-875.

92. Karkanaki A, Vosnakis C, Panidis D. The clinical significance of Anti-müllerian hormone evaluation in gynecological endocrinology. Hormones (Athens) 2011; 10: 95-103.

93. Fanchin R, Mendez Lozano DH, Frydman N, Gougeon A, di Clemente $\mathbf{N}$, Frydman $\mathbf{R}$, et al. Anti-müllerian hormone concentrations in the follicular fluid of the preovulatory follicle are predictive of the implantation potential of the ensuing embryo obtained by in vitro fertilization. J Clin Endocrinol Metab 2007; 92: 17961802.

94. Wunder DM, Guibourdenche J, Birkhauser MH, Bersinger NA. Anti-müllerian hormone and inhibin B as predictors of pregnancy after treatment by in vitro fertilization/intracytoplasmic sperm injection. Fertil Steril 2008; 90: 2203-2210.

95. de Vet A, Laven JS, de Jong FH, Themmen AP, Fauser BC. Antimüllerian hormone serum levels: a putative marker for ovarian aging. Fertil Steril 2002; 77: 357362.

96. Fanchin R, Schonauer LM, Righini C, Guibourdenche J, Frydman R, Taieb J. Serum Anti-müllerian hormone is more strongly related to ovarian follicular status than serum inhibin B, estradiol, FSH and LH on day 3. Hum Reprod 2003; 18: 323-327.

97. van Rooij IA, Tonkelaar I, Broekmans FJ, Looman CW, Scheffer GJ, de Jong FH, et al. Anti-müllerian hormone is a promising predictor for the occurrence of the menopausal transition. Menopause 2004; 11: 601606.

98. Harlow SD, Gass M, Hall JE, Lobo R, Maki P, Rebar RW, et al. Executive summary of the Stages of Reproductive Aging Workshop + 10: addressing the unfinished agenda of staging reproductive aging. Menopause 2012; 19: 387-395. 
99. Dolleman M, Depmann M, Eijkemans MJ, Heimensem J, Broer SL, van der Stroom EM, et al. Anti-müllerian hormone is a more accurate predictor of individual time to menopause than mother's age at menopause. Hum Reprod 2014; 29: 584-591.

100. Ramezani Tehrani F, Dolleman M, van Disseldorp J, Broer SL, Azizi F, Solaymani-Dodaran M, et al. Predicting menopausal age with Anti-müllerian hormone: a cross-validation study of two existing models. Climacteric 2014; 17: 583-590.

101. Lie Fong S, Lugtenburg PJ, Schipper I, Themmen AP, de Jong $\mathbf{F H}$, Sonneveld $\mathbf{P}$, et al. Anti-müllerian hormone as a marker of ovarian function in women after chemotherapy and radiotherapy for haematological malignancies. Hum Reprod 2008; 23: 674-678.

102. Giuseppe L, Attilio G, Edoardo DN, Loredana G, Cristina L, Vincenzo L. Ovarian function after cancer treatment in young women affected by Hodgkin disease (HD). Hematology 2007; 12: 141-147.

103. Brougham MF, Crofton PM, Johnson EJ, Evans N, Anderson RA, Wallace WH. Anti-müllerian hormone is a marker of gonadotoxicity in pre- and postpubertal girls treated for cancer: a prospective study. J Clin Endocrinol Metab 2012; 97: 2059-2067.

104. Lunsford AJ, Whelan K, McCormick K, McLaren JF. Antimüllerian hormone as a measure of reproductive function in female childhood cancer survivors. Fertil Steril 2014; 101: 227-231.

105. Dillon KE, Sammel MD, Prewitt M, Ginsberg JP, Walker D, Mersereau JE, et al. Pretreatment antimüllerian hormone levels determine rate of posttherapy ovarian reserve recovery: acute changes in ovarian reserve during and after chemotherapy. Fertil Steril 2013; 99: 477-483.

106. Anderson RA, RosendahI M, Kelsey TW, Cameron DA. Pretreatment Anti-müllerian hormone predicts for loss of ovarian function after chemotherapy for early breast cancer. Eur J Cancer 2013; 49: 3404-3411.

107. Urman B, Alper E, Yakin K, Oktem O, Aksoy S, Alatas C, et al. Removal of unilateral endometriomas is associated with immediate and sustained reduction in ovarian reserve. Reprod Biomed Online 2013; 27: 212-216.

108. Raffi F, Metwally M, Amer S. The impact of excision of ovarian endometrioma on ovarian reserve: a systematic review and meta-analysis. J Clin Endocrinol Metab 2012; 97: 3146-3154.

109. Somigliana E, Berlanda N, Benaglia L, Vigano P, Vercellini P, Fedele L. Surgical excision of endometriomas and ovarian reserve: a systematic review on serum antimüllerian hormone level modifications. Fertil Steril 2012; 98: 1531-1538.

110. Grynnerup AG, Lindhard A, Sorensen S. Anti-müllerian hormone levels in salpingectomized compared with nonsalpingectomized women with tubal factor infertility and women with unexplained infertility. Acta Obstet Gynecol Scand 2013; 92: 1297-1303.

111. Ni L, Sadiq S, Mao Y, Cui Y, Wang W, Liu J. Influence of various tubal surgeries to serum antimüllerian hormone level and outcome of the subsequent IVF-ET treatment. Gynecol Endocrinol 2013; 29: 345-349.

112. Sahmay S, Usta T, Erel CT, Imamoglu M, Kucuk M, Atakul $\mathbf{N}$, et al. Is there any correlation between amh and obesity in premenopausal women? Arch Gynecol Obstet 2012; 286: 661-665.

113. Rachon D, Teede H. Ovarian function and obesity--interrelationship, impact on women's reproductive lifespan and treatment options. Mol Cell Endocrinol 2010; 316: 172-179.

114. Metwally M, Ledger WL, Li TC. Reproductive endocrinology and clinical aspects of obesity in women. Ann N Y Acad Sci 2008; 1127: 140-146.

115. Piouka A, Farmakiotis D, Katsikis I, Macut D, Gerou S, Panidis D. Anti-müllerian hormone levels reflect severity of PCOS but are negatively influenced by obesity: relationship with increased luteinizing hormone levels. Am J Physiol Endocrinol Metab 2009; 296: E238-243.

116. Katsikis I, Karkanaki A, Misichronis G, Delkos D, Kandaraki EA, Panidis D. Phenotypic expression, body mass index and insulin resistance in relation to $\mathrm{LH}$ levels in women with polycystic ovary syndrome. Eur J Obstet Gynecol Reprod Biol 2011; 156: 181-185.

117. Merhi ZO, Minkoff H, Feldman J, Macura J, Rodriguez C, Seifer DB. Relationship of bariatric surgery to Müllerian-inhibiting substance levels. Fertil Steril 2008; 90 : 221-224.

118. Thomson RL, Buckley JD, Moran LJ, Noakes M, Clifton PM, Norman RJ, et al. The effect of weight loss on Anti-müllerian hormone levels in overweight and obese women with polycystic ovary syndrome and reproductive impairment. Hum Reprod 2009; 24: 1976-1981.

119. Baker ML, Metcalfe SA, Hutson JM. Serum levels of müllerian inhibiting substance in boys from birth to 18 years, as determined by enzyme immunoassay. J Clin Endocrinol Metab 1990; 70: 11-15.

120. Hudson PL, Dougas I, Donahoe PK, Cate RL, Epstein J, Pepinsky RB, et al. An immunoassay to detect human müllerian inhibiting substance in males and females during normal development. J Clin Endocrinol Metab 1990; 70: 16-22.

121. Josso N, Legeai L, Forest MG, Chaussain JL, Brauner R. An enzyme linked immunoassay for Anti-müllerian hormone: a new tool for the evaluation of testicular function in infants and children. J Clin Endocrinol Metab 1990; 70: 23-27.

122. Carre-Eusebe D, Imbeaud S, Harbison M, New MI, Josso N, Picard JY. Variants of the Anti-müllerian hormone gene in a compound heterozygote with the persistent Müllerian duct syndrome and his family. Hum Genet 1992; 90: 389-394.

123. Long WQ, Ranchin V, Pautier $\mathbf{P}$, Belville $\mathbf{C}$, Denizot $\mathbf{P}$, Cailla $\mathbf{H}$, et al. Detection of minimal levels of serum Anti-müllerian hormone during follow-up of patients with ovarian granulosa cell tumor by means of a highly sensitive enzyme-linked immunosorbent assay. J Clin Endocrinol Metab 2000; 85: 540-544.

124. Al-Qahtani A, Muttukrishna S, Appasamy M, Johns J, Cranfield M, Visser JA, et al. Development of a sensitive enzyme immunoassay for Anti-müllerian hormone 
and the evaluation of potential clinical applications in males and females. Clin Endocrinol (Oxf) 2005; 63: 267-273.

125. Freour T, Mirallie S, Bach-Ngohou K, Denis M, Barriere $\mathbf{P}$, Masson D. Measurement of serum Anti-müllerian hormone by Beckman Coulter ELISA and DSL ELISA: comparison and relevance in assisted reproduction technology (ART). Clin Chim Acta 2007; 375: 162-164.

126. Kumar A, Kalra B, Patel A, McDavid L, Roudebush WE. Development of a second generation Anti-müllerian hormone (AMH) ELISA. J Immunol Methods 2010; 362: 51-59.

127. Nelson SM, La Marca A. The journey from the old to the new AMH assay: how to avoid getting lost in the values. Reprod Biomed Online 2011; 23: 411-420.

128. Ansh Labs LLC. Ultra-Sensitive AMH/MIS ELISA. 2014. Disponible: https://www.anshlabs.com/wp-content/ uploads/inserts/AL105.pdf. Consultado: jun 2017.

129. Groome N. The design features and performance of a state-of-the-art fully-automated Anti-müllerian hormone assay for the Beckman Access Family of immunoassay systems. 2015. Beckman Coulter. Disponible: http://www.beckmancoulter-amh.com/en/ wp-content/uploads/Access-AMH-Technical-Bulletin-14-07-2015.pdf. Consultado: jun 2017.

130. Roche Diagnostics International Ltd. Elecsys ${ }^{\circledR} \mathrm{AMH}$. 2014. Disponible: http://www.cobas.com/content/dam/ cobas_com/pdf/product/Elecsys\%20AMH/Elecsys $\% 20$ AMH\%20FactSheet.pdf. Consultado: jun 2017.

131. Li HW, Wong BP, Ip WK, Yeung WS, Ho PC, Ng EH. Comparative evaluation of three new commercial immunoassays for Anti-müllerian hormone measurement. Hum Reprod 2016; 31: 2796-2802.

132. Mayo Medical Laboratories. Antimüllerian Hormone
(AMH), Serum. 2017. Mayo Foundation for Medical Education and Research. Disponible: https://www. mayomedicallaboratories.com/test-catalog/Overview/89711. Consultado: jun 2017.

133. Welsh P, Smith K, Nelson SM. A single-centre evaluation of two new Anti-müllerian hormone assays and comparison with the current clinical standard assay. Hum Reprod 2014; 29: 1035-1041.

134. Broer SL, Eijkemans MJ, Scheffer GJ, van Rooij IA, de Vet A, Themmen AP, et al. Anti-müllerian hormone predicts menopause: a long-term follow-up study in normoovulatory women. J Clin Endocrinol Metab 2011; 96: 2532-2539.

135. Nair S, Slaughter JC, Terry JG, Appiah D, Ebong I, Wang $E$, et al. Anti-müllerian hormone (AMH) is associated with natural menopause in a population-based sample: The CARDIA Women's Study. Maturitas 2015; 81: 493-498.

136. Kruszynska A, Slowinska-Srzednicka J. Anti-müllerian hormone (AMH) as a good predictor of time of menopause. Prz Menopauzalny 2017; 16: 47-50.

137. Nelson SM. Biomarkers of ovarian response: current and future applications. Fertil Steril 2013; 99: 963-969.

138. Practice Committee of the American Society for Reproductive Medicine. Testing and interpreting measures of ovarian reserve: a committee opinion. Fertil Steril 2012; 98: 1407-1415.

139. Broekmans FJ, Kwee J, Hendriks DJ, Mol BW, Lambalk CB. A systematic review of tests predicting ovarian reserve and IVF outcome. Hum Reprod Update 2006; 12: 685-718.

140. Al-Qahtani A, Groome NP. Editorial: Anti-müllerian hormone: Cinderella finds new admirers. J Clin Endocrinol Metab 2006; 91: 3760-3762.

\begin{abstract}
Anti-mullerian hormone is a homodimeric glycoprotein belonging to the transforming growth factor beta (TGF-B) super family. Anti-mullerian hormone plays a fundamental role in the regression of mullerian ducts in male embryo. In boys, it is produced by Sertoli cells of the testes until puberty where slowly decreases to residual values for the rest of the life. In female, it is secreted by granulosa cells of small follicles in the ovary where their levels accurately reflect the ovarian follicular reserve. Therefore, anti-mullerian hormone has been considered as extremely sensitive marker of ovarian aging and a valuable tool in the diagnosis and the recognition of recurrence of granulosa cell tumor. Anti-mullerian hormone evaluation is also of clinical importance in predicting of ovarian responsiveness, ovarian function cessation, and in assisted reproduction. In addition, anti-mullerian hormone could be a diagnostic marker of polycystic ovary syndrome in cases in which ultrasonographic examination is not possible. Finally, the measurement of serum anti-mullerian hormone levels during woman's reproductive life represents an ideal tool for the assessment of the ovarian follicular reserve. This review presents the physiological role of anti-mullerian hormone in women, as well as the main clinical benefits of its measurement and the laboratory tests available for this purpose.
\end{abstract}

Key words: anti-mullerian hormone, women, ovarian reserve, polycystic ovary syndrome, obesity, ovarian aging, tumor marker. 